\title{
ISR trình bày kết quả sơ bộ của dữ liệu ngành toán học Việt Nam tại Hội đồng Khoa học VIASM
}

\author{
Nguyễn Thanh Huyền \\ Trung tâm ISR \\ Trường Đại học Phenikaa.
}

Phenikaa Uni. (Hà Nội; ngày 13 tháng 11 năm 2020)—Ngày 13-11-2020, nhóm dữ liệu của trung tâm ISR đã có báo cáo kết quả sơ bộ của Dự án phát triển bộ cơ sở dữ liệu khoa học ngành toán Việt Nam SciMath tại Viện Nghiên cứu Cao cấp về Toán (VIASM) được chủ trì bởi GS. Ngô Bảo Châu - Giám đốc khoa học và PGS. Lê Minh Hà - Giám đốc điều hành của viện.

Được gieo mầm từ các thảo luận ban đầu năm 2017 giữa GS. Ngô Bảo Châu và TS. Vương Quân Hoàng, Trung tâm ISR, dự án SciMath chính thức khởi động vào tháng 1 năm 2020. Dự án được điều phối bởi VIASM và ISR với sự hỗ trợ của Quỹ Đổi mới Sáng tạo Phenikaa, và Chương trình Trọng điểm Quốc gia Phát triển Toán học 2010-2020.

Theo phân công, đội ISR chịu trách nhiệm về thiết kế, xây dựng hạ tầng kỹ thuật lưu trữ dữ liệu, xây dựng phần mềm quản lý, quản trị nhập liệu và kiểm soát chất lượng dữ liệu. Ngoài TS Vương Quân Hoàng, hai cán bộ ISR đi theo toàn bộ hệ thống công việc từ ban đầu là Lã Việt Phương và Hồ Mạnh Toàn. Nhóm dự án còn có đóng góp tự nguyện của nhiều người (đều có tên trong báo cáo; xem Ngo et al., 2020).

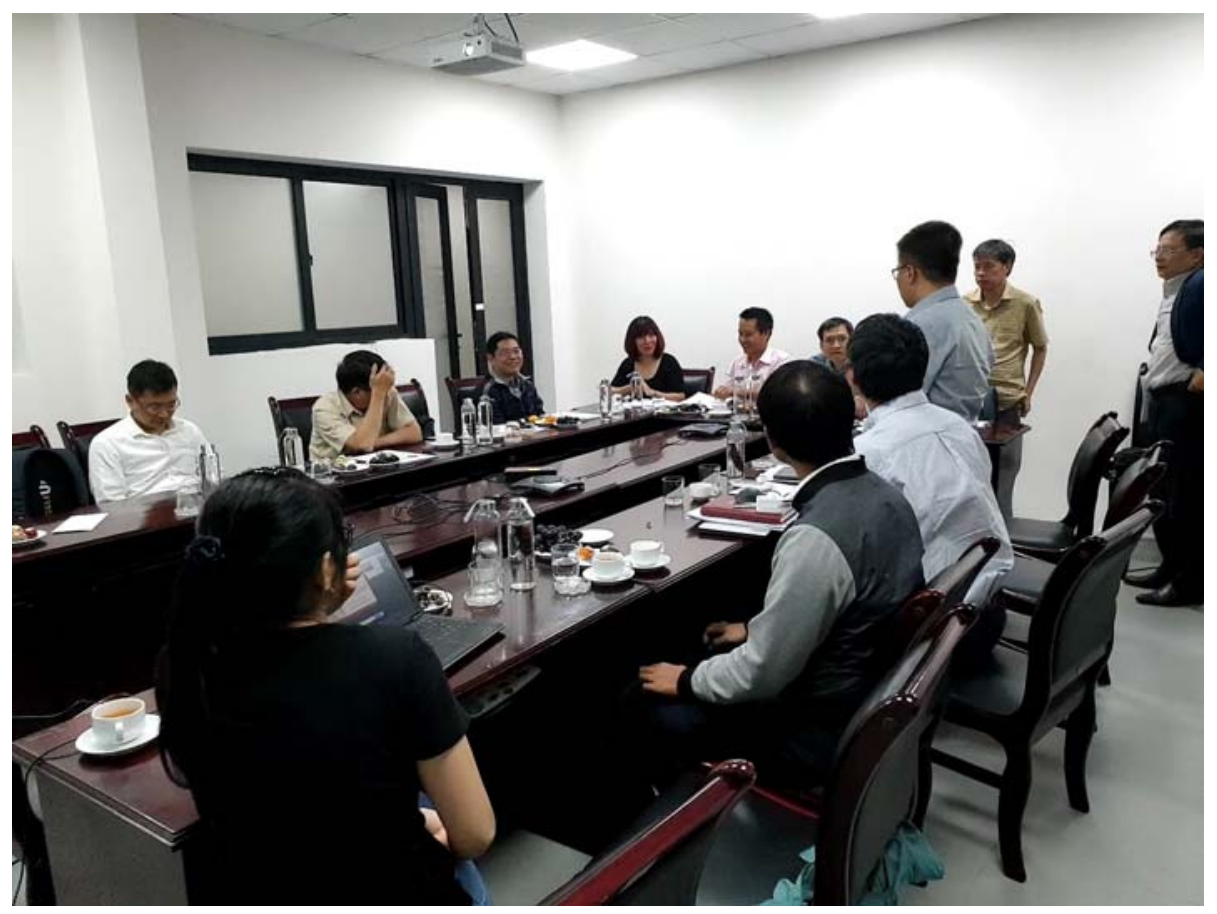

Quang cảnh phiên họp Hội đồng Khoa học VIASM 13-11-2020

Dù trải qua đúng thời gian khó khăn do dịch Covid-19, nhóm dữ liệu vẫn tiếp tục làm việc và đảm bảo đúng tiến độ dự án. Bên cạnh đó, nhóm kỹ thuật dự án cũng vượt qua vô số thách thức và thiếu thốn tài 
nguyên trong việc thực thi, thực hiện đúng triết lý đầu tư khoa học hiệu quả, giảm tối thiểu tổn thất tài chính và rủi ro kỹ thuật (Vuong, 2018).

Hôm nay, đại diện của ISR đã giới thiệu về hệ thống CSDL SciMath và trình bày về các kết quả phân tích dữ liệu đợt 1 về hoạt động nghiên cứu và công bố toán học của Việt Nam từ năm 1947 đến 2020.

Kết quả sơ bộ đã khắc họa được toàn cảnh nền toán học Việt Nam, qua hơn 70 năm lịch sử hình thành và phát triển, thông qua dữ liệu công bố quốc tế.

Dưới đây là một ví dụ về mạng lưới hợp tác nghiên cứu toán học của tác giả Việt Nam trích xuất từ CSDL SciMath (Ngo et al., 2020).

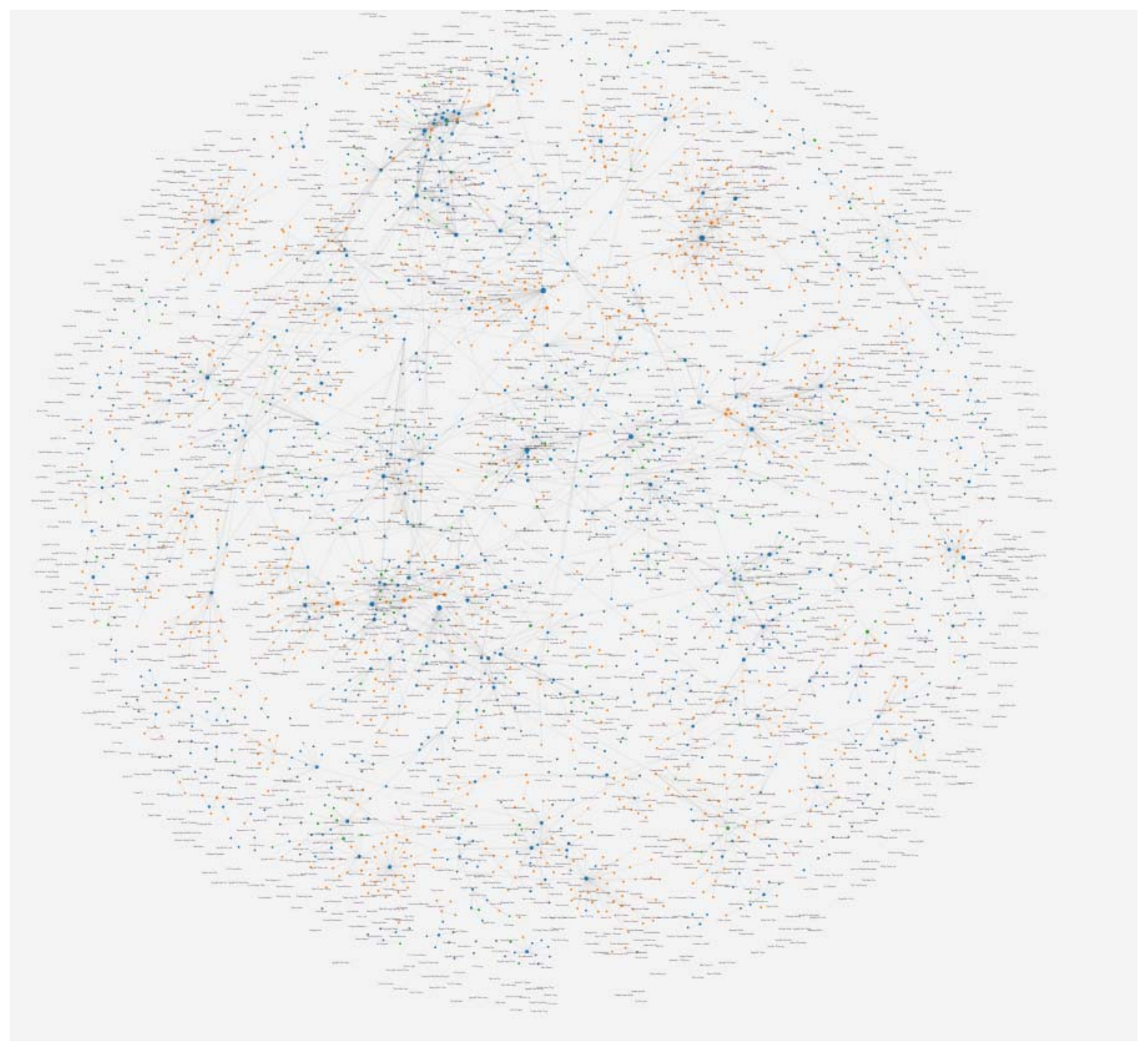

Mạng lưới hợp tác nghiên cứu toán học của tác giả Việt Nam

Các kết quả và nhận thức thú vị từ dữ liệu đã được thảo luận. GS Ngô Bảo Châu và các nhà toán học đánh giá cao chất lượng công việc. GS Ngô Bảo Châu cảm ơn nỗ lực không mệt mỏi của đội ngũ, và cho biết cả kết quả lẫn trình bầy của nhóm nghiên cứu đều "rất ấn tượng". 
Trong kế hoạch tới đây, nhóm dữ liệu sẽ tiếp tục phát triển CSDL dữ liệu SciMath để phục vụ cộng đồng toán học và công chúng. Dự án SciMath hứa hẹn sẽ tiếp tục đóng góp thêm nhiều sản phẩm trong những tháng tới đây, hỗ trợ công tác nghiên cứu và truyền thông khoa học của VIASM.

\section{References}

Ngo, B.-C, Vuong, Q.-H., La, V.-P., Le, T.-H., Le, M.-H., Trinh, T.-T. G., ... Ho, M.-T. (2020). Dự án Phát triển bộ cơ sở dữ liệu khoa học ngành toán của Việt Nam: Một số kết quả sơ bộ ban đầu từ CSDL SciMath. OSF Preprint; doi:10.31219/osf.io/9d4bv

Vuong, Q.-H. (2018). The (ir)rational consideration of the cost of science in transition economies. Nature Human Behaviour, 2(1), 5. 